\title{
A Rapid, Isocratic HPLC Method for Determination of Insulin and Its Degradation Product
}

\author{
Ahmad Najjar, ${ }^{1}$ Mahmoud Alawi, ${ }^{2}$ Najiah AbuHeshmeh, ${ }^{1}$ and Alsayed Sallam ${ }^{3}$ \\ ${ }^{1}$ College of Pharmacy, Department of Pharmaceutical Chemistry, Al-Jouf University, Sakaka, Saudi Arabia \\ ${ }^{2}$ Faculty of Science, Department of Chemistry, The University of Jordan, P.O. Box 13003, Amman 11942, Jordan \\ ${ }^{3}$ Al-Taqaddom Pharmaceutical Industries Company, Amman, Jordan
}

Correspondence should be addressed to Mahmoud Alawi; alawima@ju.edu.jo

Received 7 April 2014; Revised 2 June 2014; Accepted 10 June 2014; Published 23 July 2014

Academic Editor: Maria J. Morilla

Copyright (C) 2014 Ahmad Najjar et al. This is an open access article distributed under the Creative Commons Attribution License, which permits unrestricted use, distribution, and reproduction in any medium, provided the original work is properly cited.

\begin{abstract}
This paper aimed to develop a simple, sensitive, and rapid chromatographic procedure for the simultaneous analysis of human insulin and its main decomposition product using isocratic RP-HPLC/UV. A column type RP-C18 $(100 \times 4.6 \mathrm{~mm}, 3 \mu \mathrm{m}$ particle size, and pore size $130 \AA$ ) was used. $o$-Nitrophenol was used as internal standard. The eluent consists of $62 \% \mathrm{KH}_{2} \mathrm{PO}_{4}$ buffer $(0.1 \mathrm{M})$, $26 \% \mathrm{ACN}$, and $12 \% \mathrm{MeOH}$. The final $\mathrm{pH}$ was adjusted to 3.1. The eluent was pumped at a flow rate of $1.0 \mathrm{~mL} / \mathrm{min}$ and the effluent was monitored using DAD detector at $214 \mathrm{~nm}$. The method produces a linear response over the concentration range of 0.0106 to $0.6810 \mathrm{mg} / \mathrm{mL}$ with detection limit of $0.0029 \mathrm{mg} / \mathrm{mL}$. Considering the specifications of this method, the system was found to be suitable for rapid, direct routine analysis and stability studies of insulin.
\end{abstract}

\section{Introduction}

Since insulin was discovered in 1921 by Frederick Banting and Charles Best, it has become one of the most thoroughly studied molecules in scientific history. Insulin is a pancreatic hormone that treats diabetes by controlling the amount of sugar in the blood. This peptide hormone is composed of 51 amino acids distributed between two peptides chains, one comprising 21 amino acids (chain A) and the other 30 amino acids (chain B). The two chains are joined together by two disulfide bonds between two cysteine residues, where a disulfide bond is the linkage bond between two sulfurs [1].

Like most proteins, insulin is not stable in aqueous solutions. Its degradation mainly goes through hydrolytic reactions (deamidation) or polymerization mechanisms. Deamidation at asparagine amino acid in chain A of insulin (A21) is considered as the main degradation product of insulin at low $\mathrm{pH}$ values, while in neutral or alkaline medium, deamidation at asparagine B3 occurs [2]. Polymerization may also occur in neutral and alkaline medium through transamidation reactions [3]. As a diabetes medicine, the purity of recombinant insulin must be more than $98 \%$, with the insulin-related compound A21 desamido insulin being less than $2 \%[4,5]$. Most commercial insulin preparations are containing low concentrations of phenol and/or $m$-cresol as preservatives from bacterial contaminations.

Separation of insulin and its related compounds is a difficult mission due to the insignificant differences in chemical structures. Many immune and nonimmune methods have been reported for determination of human insulin. Radioimmunoassay [6-9], enzyme immunoassay [10-13], luminescent immunoassay [14], capillary electrophoresis [15-17], and high performance liquid chromatography (HPLC) [18-24] had been widely used for human insulin detection in vivo and in vitro.

In the determination of insulin in commercial products using RP-HPLC, chromatographic procedure should effectively separate insulin from its major degradation products, such as A21 desamido insulin, and eliminate the interference from the vial additives such as phenol or $m$-cresol. Although many researchers reported the determination of insulin content using HPLC as a powerful technique for purity determinations of proteins [18-24], most of the assays failed to achieve adequate resolution between insulin and its desamido form due to poor chromatographic conditions [5, 24]. Most of these methods tried to control the degree of insulin ionization 
by using a mobile phase with low $\mathrm{pH}$ and high salinity, which affect the column pressure and led to response fluctuations. Other methods applied the use of gradient mobile phase but were considered time consuming and not applicable for routine analysis because of high retention time (20-45 min). Other limitations of the published methods are applying an ion-pairing reagent, special columns or column temperature controller which is not popular in most of the analytical laboratories.

This paper aimed to develop a rapid and effective chromatographic procedure for simultaneous analysis of human insulin and its main decomposition product, using isocratic RP-HPLC method which also applied the addition of internal standard. The developed chromatographic method was successfully validated in terms of selectivity, linearity, precision, accuracy, solution stability, LOD and LOQ.

\section{Experimental}

\subsection{Materials and Methods}

2.1.1. Chemicals and Reagents. The chemicals needed with their purity grade and the sources of purchasing are as follows: methanol-HPLC grade from TEDIA (Fairfield, USA), acetonitrile-HPLC grade from Merck (Darmstadt, Germany), hydrochloric acid 32\% from Panreac (Barcelona/ Spain), o-phosphoric acid 85\% from Panreac (Barcelona/ Spain), phenol-extra pure from Across (Geel, Belgium), mcresol-pure from Across (Geel, Belgium), o-nitrophenol 99\% from Across (Geel, Belgium), potassium dihydrogen phosphate-analytical grade from Merck (Darmstadt, Germany), and human insulin from Biocon (Navarangpura/India).

2.1.2. Instrumentation. The HPLC system consisted of a Thermo Spectra Physics delivery pump (P2000 pump, TSP) equipped with a 6-valve sample injection port (7725i, Rheodyne) fitted with a $20 \mu \mathrm{L}$ sample loop, a diode array detector model (2800 Knauer), and integration software (EuroChrom, Knauer).

2.1.3. Method Development. Insulin, as all large molecules, does not easily gives sharp chromatography peak, but usually gives a broad peak with tailing. Another problem is to get good chromatographic resolution between insulin and insulin-like molecules (degraded products) in acceptable retention time. Finally it is important to use internal standard in the insulin determination method because of fluctuated response of insulin. The method was developed for the determination of insulin in the presence of main degraded product (A21 desamido insulin) and common vial additives like phenol and $m$-cresol and also in the presence of internal standard with suitable run time and commonly available instruments.

During the development, the researchers persist to apply isocratic HPLC system with safe mobile phase (not highly saline, $\mathrm{pH}$ more than 2.5 , and acceptable flow rate). By trying different columns (RP-C2, RP-C8, and RP-C18) from different manufacturers with different lengths $(25.0,15.0,12.5$, and
$10.0 \mathrm{~cm}$ ) and constant internal diameter of $4.6 \mathrm{~mm}$ and using different mobile phases prepared from different solvents as methanol $(\mathrm{MeOH})$, acetonitrile $(\mathrm{ACN})$, and aqueous buffer solutions at different pHs $(<2.5)$, the following chromatographic conditions were adopted:

column: Hypersil RP-C18, $100 \times 4.6 \mathrm{~mm}, 3 \mu \mathrm{m}$ particle size (pore size $130 \AA$ ) from Thermo Scientific (New Hampshire, USA);

detector: Diode Array Detector model 2800 Knauer (Berlin/Germany);

wavelength: $214 \mathrm{~nm}$;

sample injection loop: $20 \mu \mathrm{L}$;

flow rate: $1.0 \mathrm{~mL} / \mathrm{min}$;

elution mode: isocratic;

mobile phase: $62 \% \mathrm{KH}_{2} \mathrm{PO}_{4}$ buffer $(0.1 \mathrm{M}), 26 \% \mathrm{ACN}$, and $12 \% \mathrm{MeOH}$; the final $\mathrm{pH}$ was adjusted to 3.1.

2.1.4. Preparation of Internal Standard (IS) Stock Solution (I). $0.2000 \mathrm{~g}$ of $o$-nitrophenol was dissolved in $1.0 \mathrm{~L}$ of $0.01 \mathrm{M} \mathrm{HCl}$ to make a solution of $0.2000 \mathrm{mg} / \mathrm{mL}$ internal standard (IS).

2.1.5. Preparation of Internal Standard (IS) Stock Solution (II). $20.0 \mathrm{~mL}$ of IS stock solution (I) was further diluted by addition of $80.0 \mathrm{~mL} 0.01 \mathrm{M} \mathrm{HCl}$ to give a concentration of $0.0400 \mathrm{mg} / \mathrm{mL}$.

2.1.6. Preparation of Insulin Stock Solution (I). $0.1362 \mathrm{~g}$ of Insulin was dissolved in $100 \mathrm{~mL}$ of $0.01 \mathrm{M} \mathrm{HCl}$ solution; this will give an insulin solution with the concentration of $1.362 \mathrm{mg} / \mathrm{mL}$. The solution was kept in refrigerator $\left(<5^{\circ} \mathrm{C}\right)$ for not more than two days [24].

2.1.7. Preparation of Insulin Stock Solution (II). $12.5 \mathrm{~mL}$ of insulin stock solution (I) was diluted to $100 \mathrm{~mL}$ with $0.01 \mathrm{M}$ $\mathrm{HCl}$ to give a solution of insulin with a concentration of $0.17025 \mathrm{mg} / \mathrm{mL}$. The solution was kept in refrigerator $\left(<5^{\circ} \mathrm{C}\right)$ for not more than three days.

2.1.8. Preparation of A-21 Desamido Insulin. $10 \mathrm{~mL}$ aliquot of insulin stock solution (I) was transferred to a clean test tube and incubated at $35^{\circ} \mathrm{C}$ for 4 days [25].

2.1.9. Phenol and $m$-Cresol Mixture. $0.600 \mathrm{~g}$ of each phenol and $m$-cresol were dissolved in $25.0 \mathrm{~mL}$ deionized water and few drops of methanol. $200 \mu \mathrm{L}$ of this mixture with $25 \mathrm{~mL}$ of IS stock solution (I) was diluted to $100 \mathrm{~mL}$ with $0.01 \mathrm{M} \mathrm{HCl}$ to give a final concentration of $0.0480 \mathrm{mg} / \mathrm{mL}$ for each phenol and $m$-cresol and $0.0400 \mathrm{mg} / \mathrm{mL}$ for IS.

2.1.10. Preparation of Standard Insulin Solutions for the Calibration Curve. For the preparation of an insulin calibration curve, eight standard solutions were prepared in the concentration range between 0.0106 and $0.6810 \mathrm{mg} / \mathrm{mL}$. 


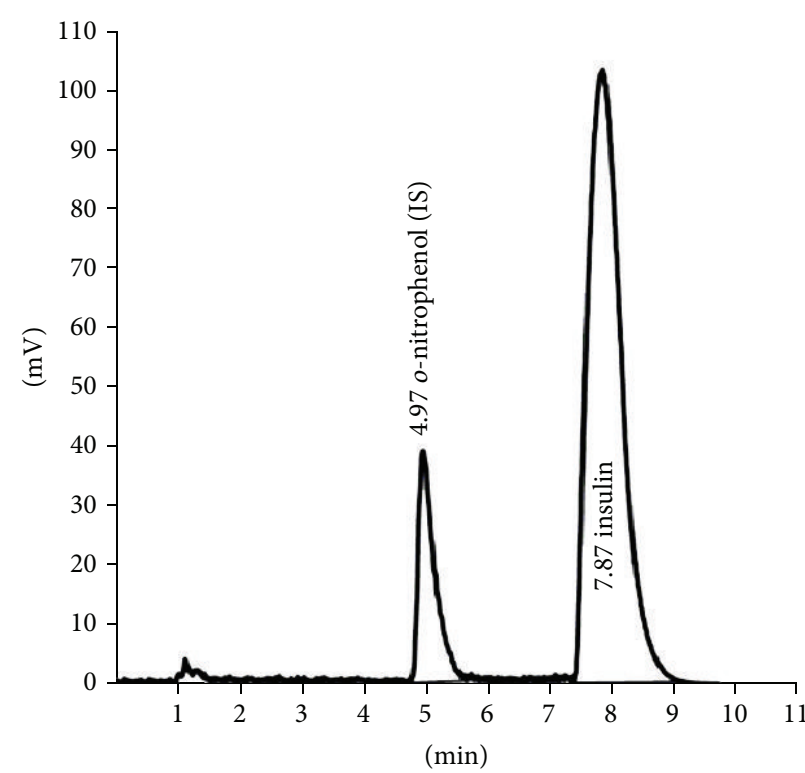

(a)

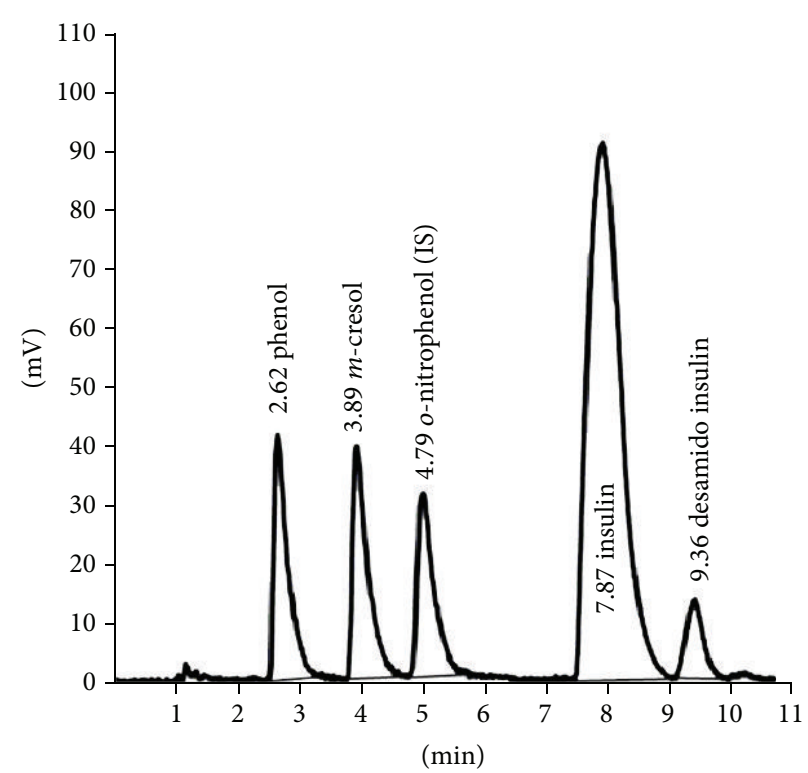

(b)

FIGURE 1: (a) Insulin standard in addition of IS (o-nitrophenol). (b) Degraded insulin in addition of IS (o-nitrophenol) and vial additives (phenol and $m$-cresol).

TABLE 1: Insulin calibration curve data.

\begin{tabular}{lcccccr}
\hline Con. $(\mathrm{mg} / \mathrm{mL})$ & Cal. 1 & Cal. 2 & Cal. 3 & Cal. 4 & Average & SD \\
& AR $^{*}$ & AR & AR & AR & RSD \% \\
\hline 0.6810 & 11.8730 & 11.8194 & 11.8894 & 11.9334 & 11.8788 & 0.0471 \\
0.3405 & 5.8769 & 5.7887 & 5.8790 & 5.8062 & 5.8377 & 0.0471 \\
0.1703 & 3.0726 & 3.0054 & 3.0551 & 3.0715 & 3.0512 & 0.0315 \\
0.0851 & 1.4171 & 1.4513 & 1.4614 & 1.4350 & 1.4412 & 0.0194 \\
0.0426 & 0.7468 & 0.7283 & 0.7324 & 0.7504 & 0.7395 & 0.0108 \\
0.0213 & 0.3682 & 0.3681 & 0.3601 & 0.3688 & 0.3663 & 0.0041 \\
0.0106 & 0.1872 & 0.1802 & 0.1792 & 0.1811 & 0.1819 & 0.0036 \\
\hline Slope & 17.4223 & 17.3179 & 17.4471 & 17.4714 & 17.4147 & 0.0676 \\
Intercept & -0.0003 & -0.0088 & -0.0030 & -0.0091 & -0.0053 & 0.0044 \\
$R^{2}$ & 0.99983 & 0.99985 & 0.99989 & 0.99969 & 0.99982 & 0.00009 \\
\hline
\end{tabular}

*AR: area ratio.

2.1.11. Preparation of Quality Control (QC) Insulin Solutions. The insulin stock solution (II) with the concentration of $0.17025 \mathrm{mg} / \mathrm{mL}$ was used to prepare quality control samples with the concentrations of $0.17025,0.06810$, and $0.01703 \mathrm{mg} / \mathrm{mL}$ to check the method precision, accuracy, and stability.

\subsection{Method Validation Experiments}

2.2.1. Selectivity and Interference of Additives. Selectivity of the method was studied by processing blank solutions $(0.01 \mathrm{M}$ $\mathrm{HCl}$ ) and mixture solution of insulin, A21 desamido insulin, IS, and vial additives (phenol and $m$-cresol). $2.0 \mathrm{~mL}$ of phenol and $m$-cresol mixture was diluted with $2.0 \mathrm{~mL}$ of A21 desamido solution (prepared as previously described); this mixture was processed and compared with a solution of freshly prepared insulin (standard 1). Chromatograms are depicted in Figure 1.

2.2.2. Linear Range. The linear range is important to clarify the concentration range where the relation between the concentrations and signals is linear. From the development experiments, it was shown that the method is linear up to insulin concentration of $0.6810 \mathrm{mg} / \mathrm{mL}$ in $0.01 \mathrm{M} \mathrm{HCl}$. In order to validate this assumption, four sets of calibration standard solutions containing seven concentrations ranging from 0.0106 to $0.6810 \mathrm{mg} / \mathrm{mL}$ were freshly prepared as shown in Table 1. These solutions were injected in duplicate, and accumulated chromatograms of these standard solutions are represented in Figure 2. The relative peak areas (peak area of insulin/peak area of IS) were plotted against the nominal concentrations of insulin solutions and linearity was tested 
TABLE 2: Data of precision experiment ( $n=6$, each preparation was injected twice).

\begin{tabular}{|c|c|c|c|c|c|c|c|c|c|c|}
\hline \multirow[t]{2}{*}{ Conc. } & \multicolumn{5}{|c|}{$0.06810 \mathrm{mg} / \mathrm{mL}$} & \multicolumn{5}{|c|}{$0.01703 \mathrm{mg} / \mathrm{mL}$} \\
\hline & Ins. area & IS area & $\mathrm{AR}$ & Ave. & Conc. & Ins. area & IS area & $\mathrm{AR}$ & Ave. & Conc. \\
\hline & 9.9868 & 8.1734 & 1.2219 & \multirow{2}{*}{1.2260} & \multirow{2}{*}{0.07070} & 2.6968 & 8.8942 & 0.3032 & \multirow{2}{*}{0.3057} & \multirow{2}{*}{0.01786} \\
\hline & 9.9792 & 8.1126 & 1.2301 & & & 2.7007 & 8.7643 & 0.3082 & & \\
\hline & 11.7923 & 9.7909 & 1.2044 & \multirow{2}{*}{1.2004} & \multirow{2}{*}{0.06923} & 2.7409 & 9.0975 & 0.3013 & \multirow{2}{*}{0.3025} & \multirow{2}{*}{0.01767} \\
\hline & 11.6048 & 9.7004 & 1.1963 & & & 2.7348 & 9.0055 & 0.3037 & & \\
\hline & 11.6483 & 9.5581 & 1.2187 & \multirow{2}{*}{1.2212} & \multirow{2}{*}{0.07043} & 2.8628 & 9.7853 & 0.2926 & \multirow{2}{*}{0.2926} & \multirow{2}{*}{0.01711} \\
\hline & 11.6895 & 9.5531 & 1.2236 & & & 2.8648 & 9.7891 & 0.2926 & & \\
\hline & 10.9214 & 9.0979 & 1.2004 & \multirow{2}{*}{1.2117} & \multirow{2}{*}{0.06988} & 3.1066 & 10.1297 & 0.3067 & \multirow{2}{*}{0.3081} & \multirow{2}{*}{0.01800} \\
\hline & 11.0028 & 8.9965 & 1.2230 & & & 3.1642 & 10.2212 & 0.3096 & & \\
\hline & 11.2385 & 9.2503 & 1.2149 & \multirow{2}{*}{1.2206} & \multirow{2}{*}{0.07039} & 3.1953 & 10.6644 & 0.2996 & \multirow{2}{*}{0.2989} & \multirow{2}{*}{0.01747} \\
\hline & 11.3289 & 9.2381 & 1.2263 & & & 3.1761 & 10.6510 & 0.2982 & & \\
\hline & 10.8315 & 8.9431 & 1.2116 & \multirow{2}{*}{1.2003} & \multirow{2}{*}{0.06923} & 2.9253 & 9.6708 & 0.3025 & \multirow{2}{*}{0.3048} & \multirow{2}{*}{0.01780} \\
\hline & 10.6340 & 8.9408 & 1.1894 & & & 2.9792 & 9.7013 & 0.3071 & & \\
\hline Average & & & & & 0.06998 & & & & & 0.01765 \\
\hline $\mathrm{SD}$ & & & & & 0.00064 & & & & & 0.00032 \\
\hline RSD \% & & & & & 0.91 & & & & & 1.82 \\
\hline
\end{tabular}

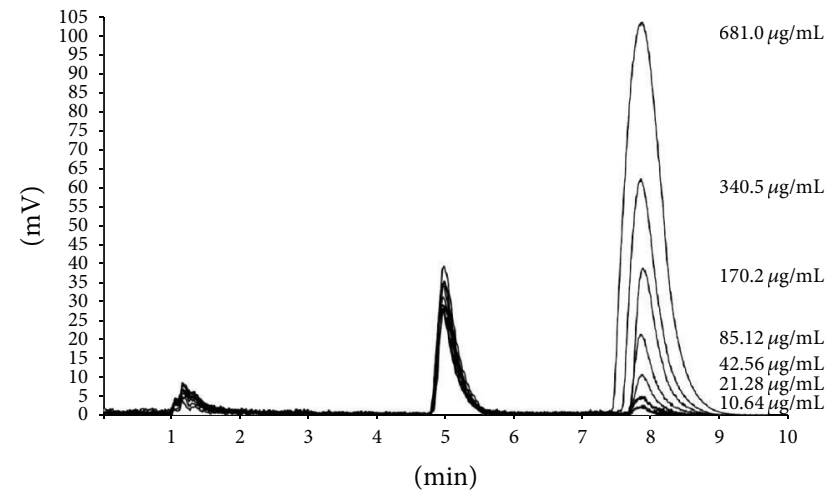

Figure 2: Chromatograms for calibration insulin standard solutions.

by calculating $R^{2}$ (correlation coefficient) value, which should be $>0.99$; Figure 3 shows the average constructed calibration curve for four sets of calibration standards.

2.2.3. Limit of Detection (LOD) and Limit of Quantitation (LOQ). LOD and LOQ were calculated based on the signalto-noise ratio. A signal-to-noise ratio $(\mathrm{S} / \mathrm{N})$ of three is generally accepted for estimating LOD and signal-to-noise ratio of ten is used for estimating LOQ [26].

2.2.4. Precision (Repeatability). Six different preparations of insulin solutions of the concentrations 0.06810 and $0.01703 \mathrm{mg} / \mathrm{mL}$ in the presence of $0.0200 \mathrm{mg} / \mathrm{mL}$ IS were prepared in $0.01 \mathrm{M} \mathrm{HCl}$. Each solution was injected twice. The average area ratio for each solution was calculated and used to calculate the concentration of these solutions using the linear equation. These back calculated concentrations were subjected to precision calculations (standard deviation and RSD\%). All these data are shown in Table 2.

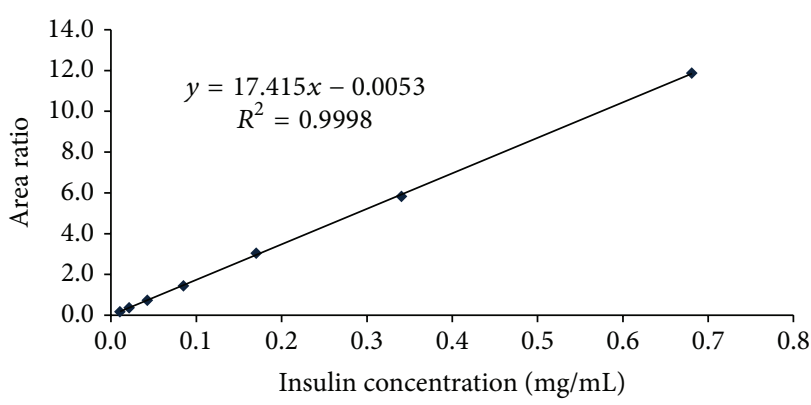

FIGURE 3: Calibration curve of insulin solution using $o$-nitrophenol as internal standard $(n=4)$.

2.2.5. Accuracy. Three different solutions were used to present the accuracy of the analytical method. Each of these solutions was injected three times and the average was calculated. The back calculated concentration for these solutions was evaluated from the slope and intercept of the calibration curve. The average, standard deviation, relative standard deviation (RSD\%), and relative error were calculated for each concentration and shown in Table 3 . These values were used to illustrate the accuracy of the method.

2.2.6. Stability. The stability was evaluated for aqueous insulin solution during analysis time and storage period. Insulin was analyzed immediately after preparation as well as after 12,24 , and $48 \mathrm{~h}$ in room temperature for the concentrations of $0.01703 \mathrm{mg} / \mathrm{mL}$ and $0.17025 \mathrm{mg} / \mathrm{mL}$. Stability was calculated as the percent ratio of concentrations determined after each storage time with respect to the fresh assay. Results are presented in Table 4.

\section{Results and Discussion}

The aim of this work was focused on developing a simple chromatographic method for insulin determination without 
TABLE 3: Data of accuracy experiments.

\begin{tabular}{|c|c|c|c|c|c|c|c|c|}
\hline Conc. $\mathrm{mg} / \mathrm{mL}$ & Insulin area & IS area & $\mathrm{AR}^{*}$ & Calc. conc. & Average calc. conc. & Standard deviation & RSD \% & Re. error \% \\
\hline \multirow{3}{*}{0.17025} & 28.45996 & 9.47664 & 3.00317 & 0.17275 & \multirow{3}{*}{0.17158} & \multirow{3}{*}{0.00158} & \multirow{3}{*}{0.92} & \multirow{3}{*}{0.78} \\
\hline & 27.98159 & 9.34673 & 2.99373 & 0.17221 & & & & \\
\hline & 25.80710 & 8.74393 & 2.95143 & 0.16978 & & & & \\
\hline \multirow{3}{*}{0.06810} & 10.95933 & 9.13004 & 1.20036 & 0.06923 & \multirow{3}{*}{0.06906} & \multirow{3}{*}{0.00045} & \multirow{3}{*}{0.65} & \multirow{3}{*}{1.41} \\
\hline & 11.27432 & 9.36966 & 1.20328 & 0.06940 & & & & \\
\hline & 11.44450 & 9.62872 & 1.18858 & 0.06855 & & & & \\
\hline \multirow{3}{*}{0.01703} & 2.85957 & 9.81390 & 0.29138 & 0.01703 & \multirow{3}{*}{0.01672} & \multirow{3}{*}{0.00029} & \multirow{3}{*}{1.73} & \multirow{3}{*}{-1.79} \\
\hline & 2.74505 & 9.63243 & 0.28498 & 0.01667 & & & & \\
\hline & 3.02176 & 10.7402 & 0.28135 & 0.01646 & & & & \\
\hline
\end{tabular}

*AR: area ratio.

TABLE 4: Stability of insulin solutions at room temperature $(n=6)$.

\begin{tabular}{lcccc}
\hline Concentration $(\mathrm{mg} / \mathrm{mL})$ & Fresh sample & 12 h sample & 24 h sample & $48 \mathrm{~h}$ sample \\
\hline 0.17025 & $98.99 \pm 1.12 \%$ & $96.31 \pm 1.36 \%$ & $93.87 \pm 0.37 \%$ & $87.33 \pm 1.31 \%$ \\
0.01703 & $100.14 \pm 0.53 \%$ & $95.45 \pm 0.98 \%$ & $86.66 \pm 1.82 \%$ & $81.73 \pm 1.27 \%$ \\
\hline
\end{tabular}

the use of sophisticated and rare gradient elution and without the employing of harsh mobile phase (low $\mathrm{pH}$ and highly salinity) or uncommon chemicals and columns. On the same time, the aimed method should be suitable for routine analysis of insulin in the presence of its major degraded product and vial additives. This was done by fine-tuning of mobile phase composition and using small particle size for stationary phase.

The use of internal standard (IS) in insulin determinations in pharmaceutical preparations is not common [18-23]. The developed method applied the use of internal standard to overcome any changes that might happen with chromatographic conditions, especially which related to the mobile phase fine composition. Several chemicals were tested as internal standard, among these $o$-nitrophenols, has been chosen as the most fitting because of its proper retention time. Figure 1 illustrates chromatograms for insulin in the presence of internal standard and insulin in the presence of its degraded product and vial additives.

The method approved its rapidity where the retention time of insulin is 7.9 minutes and that for insulin degraded product is 9.36 minutes where the repeatability is less than $0.52 \%$. The selectivity of the method was established by comparing the chromatograms of standard insulin with degraded insulin as shown in Figure 1(b). The chromatograms proved that no interferences occurred with the retention time $\left(t_{R}\right)$ of insulin peak. The method also shows good resolution $\left(R_{s}\right)$ of 1.56 between insulin and A21 desamido insulin (main degradation product).

Linearity test of the method is demonstrated by the standard solutions chromatograms presented in Figure 2 and calibration curve is depicted in Figure 3. Linearity was confirmed by correlation coefficient of 0.9998 over the range of $0.0106-0.6810 \mathrm{mg} / \mathrm{mL}$; data are listed in Table 1.

LOD and LOQ were assessed for the developed method and found to be $2.93 \mu \mathrm{g} / \mathrm{mL}$ for LOD and $9.78 \mu \mathrm{g} / \mathrm{mL}$ for LOQ.
The precision (repeatability) was tested at two different levels of insulin concentrations. Data presented in Table 2 revealed acceptable values for method precision. Relative standard deviations (RSD\%) were 1.82 for the low concentration level $(0.01703 \mathrm{mg} / \mathrm{mL})$ and 0.91 for the middle concentration level $(0.06810 \mathrm{mg} / \mathrm{mL})$.

The accuracy of the method was studied at three different concentration levels and the relative error was ranging from -1.79 to $1.41 \%$, as shown in Table 3.

Stability experiments were performed at two concentration levels $(0.17025$ and $0.01703 \mathrm{mg} / \mathrm{mL})$ to determine bench top stability (after 12, 24, and $48 \mathrm{~h}$ ) at room temperature. Stability was calculated as the percent ratio of the determined concentration after each storage time with respect to the fresh assay. The stability results are summarized in Table 4 .

The results show that insulin is stable in acidic medium $(\mathrm{pH} 2)$ at room temperature for not more than 12 hours, which is enough time for analysis. The samples should be stored in refrigerator and it is recommended to prepare fresh calibrators for each day of analysis.

\section{Conclusions}

The new developed isocratic RP-HPLC analytical method for the determination of insulin is simple, sensitive, selective, precise, accurate, and rapid with a short run time of $7.87 \mathrm{~min}$ compared to the USP method of $90 \mathrm{~min}$. The method employed a C18 column with ultraviolet detection at $214 \mathrm{~nm}$. This method was tested for the study of insulin and its desamido degradation product and in the presence of phenol and $m$-cresol which present in low concentration in the commercial insulin preparations as preservatives with good separation between their peaks. The method proved its validity and therefore can be used for the routine analysis of human insulin. $o$-Nitrophenol was successfully used as internal standard which improves the accuracy and linearity of the calibration curve. 


\section{Conflict of Interests}

The authors declare that there is no conflict of interests regarding the publication of this paper.

\section{References}

[1] J. Espinal, Understanding Insulin Action: Principles and Molecular Mechanisms, Ellis Horwood, Chichester, UK, 1989.

[2] J. Brange, L. Langkjaer, S. Havelund, and A. Volund, "Chemical stability of insulin. 1. Hydrolytic degradation during storage of pharmaceutical preparations," Pharmaceutical Research, vol. 9, no. 6, pp. 715-726, 1992.

[3] J. Brange, S. Havelund, and P. Hougaard, "Chemical stability of insulin. 2. Formation of higher molecular weight transformation products during storage of pharmaceutical preparations," Pharmaceutical Research, vol. 9, no. 6, pp. 727-734, 1992.

[4] British Pharmacopoeia, H.M. Stationary Office, London, UK, 2012.

[5] USP 35-NF 30, Philadelphia, Rockville, MD, USA, 2012.

[6] M. U. Jars, A. Hvass, and D. Waaben, "Insulin aspart(aspB28 human insulin) derivatives formed in pharmaceutical solutions," Pharmaceutical Research, vol. 19, no. 5, pp. 621-628, 2002.

[7] R. S. Yalow and S. A. Berson, "Assay of plasma insulin in human subjects by immunological methods," Nature, vol. 184, no. 4699, pp. 1648-1649, 1959.

[8] L. E. M. Miles and C. N. Hales, "Labelled antibodies and immunological assay systems,” Nature, vol. 219, no. 5150, pp. 186-189, 1968.

[9] J. F. Dezier, A. M. Jouanolle, M. Le Reun, and J. Y. Poirier, "Comparison of two methods to measure microalbuminuria: immunoephelemetry and radioimmunology," Annales de Biologie Clinique, vol. 45, no. 1, pp. 78-84, 1987.

[10] H. V. Webster, A. J. Bone, K. A. Webster, and T. J. Wilkin, "Comparison of an enzyme-linked immunosorbent assay (ELISA) with a radioimmunoassay (RIA) for the measurement of rat insulin," Journal of Immunological Methods, vol. 134, no. 1, pp. 95-100, 1990.

[11] L. Andersen, B. Dinesen, P. N. Jorgensen, F. Poulsen, and M. E. Roder, "Enzyme immunoassay for intact human insulin in serum or plasma," Clinical Chemistry, vol. 39, no. 4, pp. 578-582, 1993.

[12] H. Shen, C. A. Aspinwal, and R. T. Kennedy, "Dual microcolumn immunoassay applied to determination of insulin secretion from single islets of Langerhans and insulin in serum," Journal of Chromatography B: Biomedical Sciences and Applications, vol. 689, no. 2, pp. 295-303, 1997.

[13] K. Zaitsu, Y. Kimura, Y. Ohba et al., "Heme-undecapeptide labeling on insulin for the immunoassay of insulin with chemiluminescence detection," Analytical Sciences, vol. 15, no. 9, pp. 871-878, 1999.

[14] C. Arcelloni, L. Falqui, S. Martinenghi, A. E. Pontiroli, and R. Paroni, "Capillary electrophoresis for simultaneous quantification of human proinsulin, insulin and intermediate forms," Electrophoresis, vol. 19, no. 8-9, pp. 1475-1477, 1998.

[15] C. Yomota, Y. Matsumoto, S. Okada, Y. Hayashi, and R. Matsuda, "Discrimination limit for purity test of human insulin by capillary electrophoresis," Journal of Chromatography B: Biomedical Applications, vol. 703, no. 1-2, pp. 139-145, 1997.

[16] W. Tong and S. Edward, "Determination of insulin in single pancreatic cells by capillary electrophoresis and laser-induced native fluorescence," Journal of Chromatography B: Biomedical Sciences and Applications, vol. 685, no. 1, pp. 35-40, 1996.

[17] I. German and T. R. Kennedy, "Rapid simultaneous determination of glucagon and insulin by capillary electrophoresis immunoassays," Journal of Chromatography B: Biomedical Sciences and Applications, vol. 742, no. 2, pp. 353-362, 2000.

[18] A. Hvass and B. Skelbaek-Pedersen, "Determination of protamine peptides in insulin drug products using reversed phase high performance liquid chromatography," Journal of Pharmaceutical and Biomedical Analysis, vol. 37, no. 3, pp. 551-557, 2005.

[19] C. Toriumi and K. Imai, "Determination of insulin in a single islet of Langerhans by high-performance liquid chromatography with fluorescence detection," Analytical Chemistry, vol. 74, no. 10, pp. 2321-2327, 2002.

[20] A. Pastore, S. Bernardini, L. Dello Strologo, G. Rizzoni, C. Cortese, and G. Federici, "Simultaneous determination of inulin and $p$-aminohippuric acid in plasma and urine by reversedphase high-performance liquid chromatography," Journal of Chromatography B: Biomedical Sciences and Applications, vol. 751, no. 1, pp. 187-191, 2001.

[21] J. V. O'Connor, "Chromatography of recombinant proteins," Developments in Biological Standardization, vol. 97, pp. 39-47, 1999.

[22] G. Khaksa, K. Nalini, M. Bhat, and N. Udupa, "High-performance liquid chromatographic determination of insulin in rat and human plasma," Analytical Biochemistry, vol. 260, no. 1, pp. 9295, 1998.

[23] B. V. Fisher, D. Smith, and J. Pharm, "HPLC as a replacement for the animal response assays for insulin," Journal of Pharmaceutical and Biomedical Analysis, vol. 4, pp. 377-387, 1986.

[24] N. Abu Heshmeh, A. Sallam, Y. Mater, and M. Alawi, "A new method for determination of human insulin in aqueous injections," International Journal of Research in Pharmaceutical and Biomedical Sciences, vol. 4, no. 2, pp. 428-435, 2013.

[25] B. A. Moussa, F. Farouk, and H. M. E. Azzazy, "A validated RPHPLC method for the determination of recombinant human insulin in bulk and pharmaceutical dosage form," E-Journal of Chemistry, vol. 7, no. 1, pp. S449-S457, 2010.

[26] A. Shrivastava and V. B. Gupta, "Methods for the determination of limit of detection and limit of quantitation of the analytical methods," Chronicles of Young Scientists, vol. 2, pp. 21-25, 2011. 

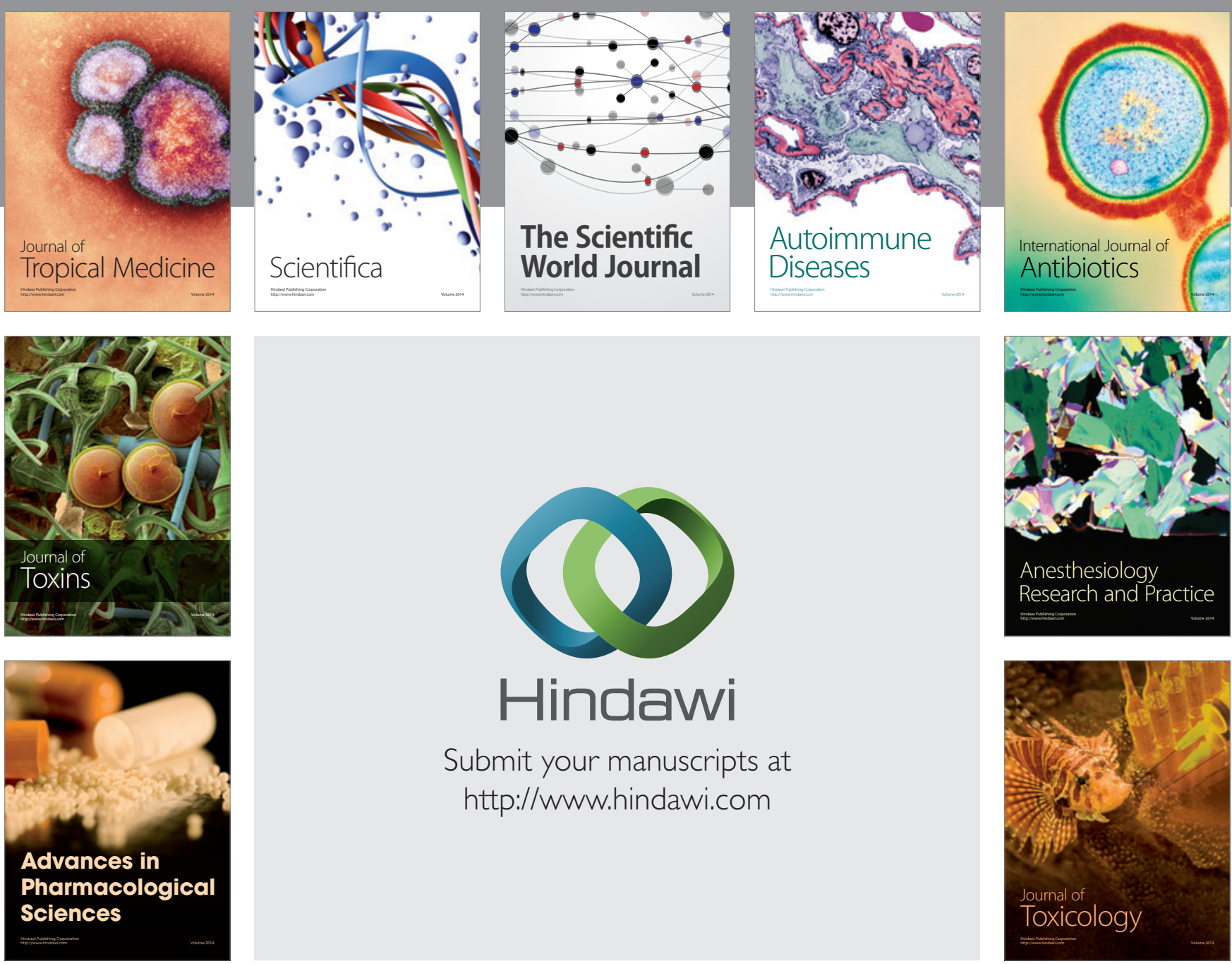

\section{Hindawi}

Submit your manuscripts at

http://www.hindawi.com
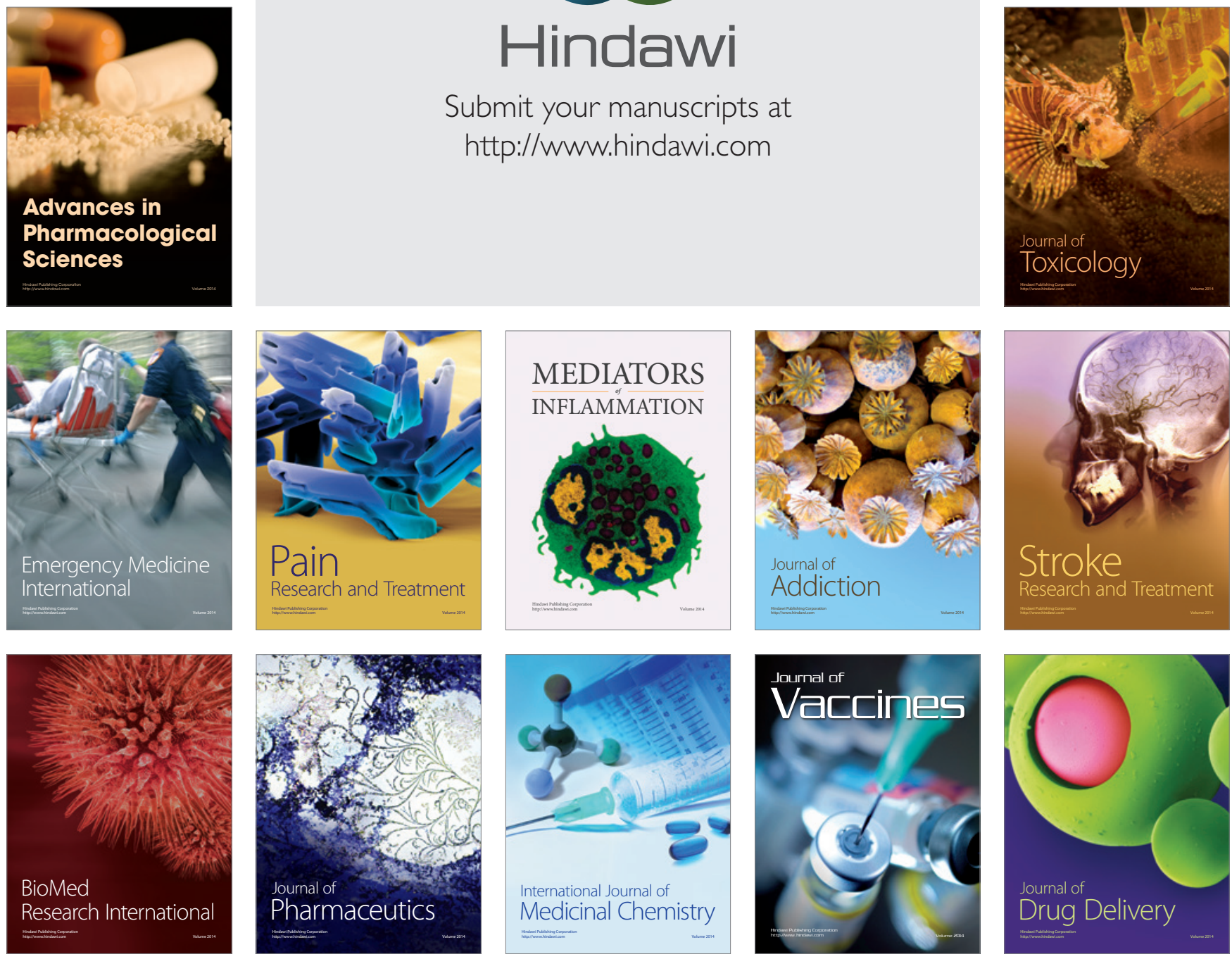